This item was submitted to Loughborough's Research Repository by the author.

Items in Figshare are protected by copyright, with all rights reserved, unless otherwise indicated.

\title{
Use of carbon nanotubes reinforced epoxy as adhesives to join aluminum plates
}

PLEASE CITE THE PUBLISHED VERSION

http://dx.doi.org/10.1016/j.matdes.2009.11.045

PUBLISHER

(C) Elsevier

VERSION

AM (Accepted Manuscript)

LICENCE

CC BY-NC-ND 4.0

\section{REPOSITORY RECORD}

Yu, Suzhu, Min Nah Tong, and Gary W. Critchlow. 2012. "Use of Carbon Nanotubes Reinforced Epoxy as Adhesives to Join Aluminum Plates”. figshare. https://hdl.handle.net/2134/9634. 
This item was submitted to Loughborough's Institutional Repository (https://dspace.lboro.ac.uk/) by the author and is made available under the following Creative Commons Licence conditions.

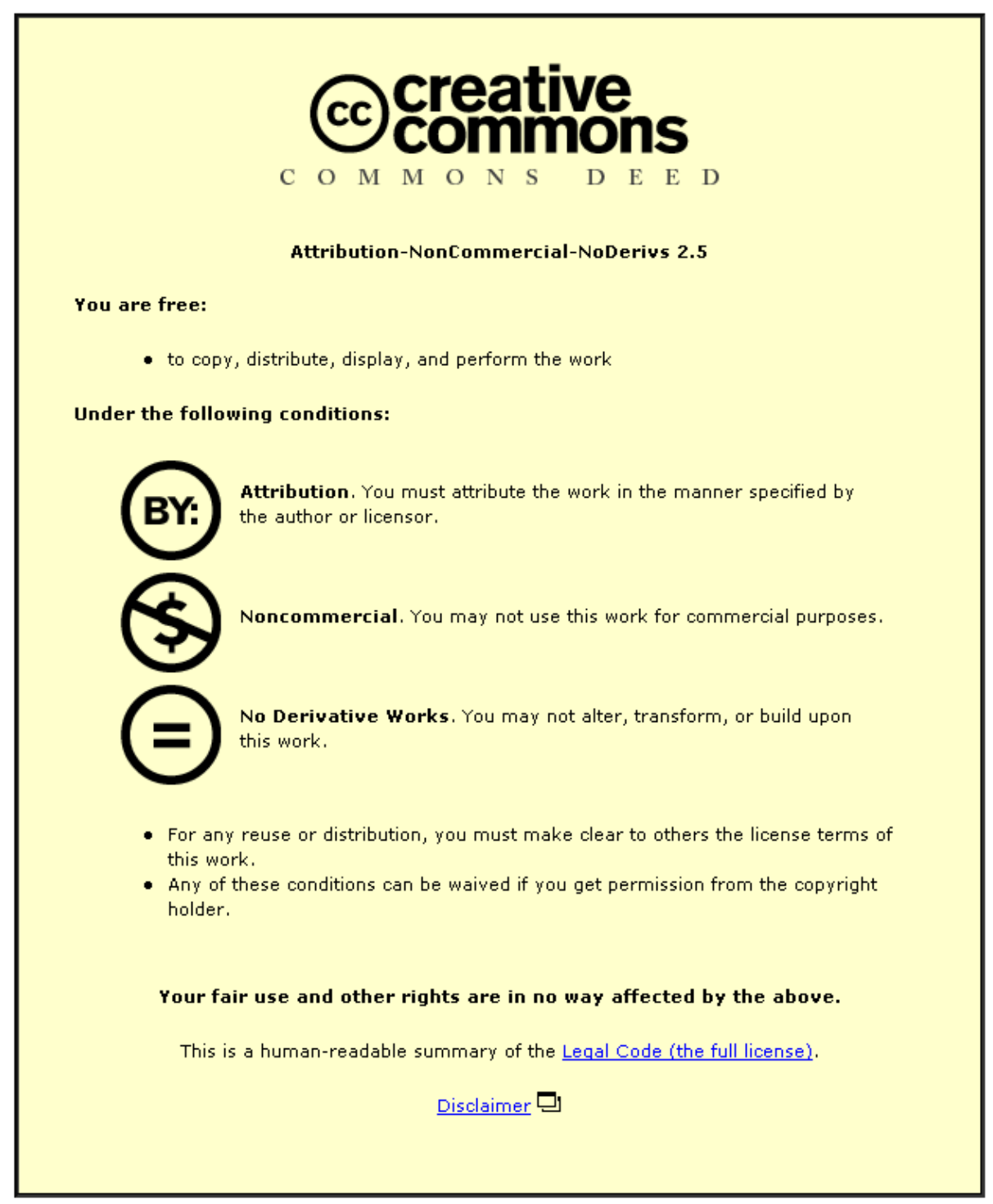

For the full text of this licence, please go to: http://creativecommons.org/licenses/by-nc-nd/2.5/ 


\title{
Use of Carbon Nanotubes Reinforced Epoxy as Adhesives to Join Aluminum Plates
}

\author{
Suzhu Yu ${ }^{1}$, Min Nah Tong ${ }^{2}$ and Gary Critchlow ${ }^{2}$ \\ ${ }^{1}$ Singapore Institute of Manufacturing Technology, 71 Nanyang Drive, Singapore \\ ${ }^{2}$ Institute of Polymer Technology and Materials Engineering, Loughborough \\ University, Leicestershire, LE11 3TU UK
}

\begin{abstract}
Carbon nanotubes (CNTs), a new form of pure carbon, have an extremely unique and desirable combination of mechanical, thermal and electrical properties. The CNT reinforced polymer composites have the potential to meet the electrical and mechanical requirements of various industries. In this paper, CNT reinforced epoxy adhesives was developed. Firstly, the distribution of the carbon nanotubes in the polymer matrix, which is crucial to the properties improvement of the adhesive, was optimized to obtain uniformly dispersed CNTs in the epoxy. Then the thermal and electrical properties of the adhesives were studied as a function of CNT fraction. It was found that the thermal stability increased with the addition of CNT, and the percolation threshold for surface electrical conductivity was less than $0.5 \mathrm{wt} \%$ of CNTs.

In order to study the adhesion properties, two aluminum alloy plates were joined together with the adhesive with different amount of CNTs. The bonding strength and durability of the joints were studied in terms of Boeing wedge test under water of $60^{\circ} \mathrm{C}$, and both of them were found to increase significantly with the incorporation of CNTs. The initial crack length of the joint with 1 wt $\%$ of CNT was only about $7 \%$ of that with neat epoxy. The joint with neat epoxy failed after 3 hours immersion into water, but all the joints adhered with different fraction of CNTs still bonded together after 90 hours of test. Nevertheless, it was also revealed from experiments that the durability of the joints showed an optimum at approximately $1 \mathrm{wt} \%$ of CNTs, beyond which a drop in the property was observed. The overall thermal, electrical and mechanical properties of the CNT reinforced epoxy adhesives present a very positive prospect to industry applications.
\end{abstract}




\section{Introduction}

Polymer adhesive bonding has been widely used in electronics, display, aerospace, automotive, and other industries ${ }^{[1,2]}$. In electronic industry, which requires high electrical conductivity of adhesives, the traditional electronic assemblies rely heavily on soldering which containing toxic lead to attach components to the interconnect wiring on printed circuit boards. Although epoxy based isotropic conductive adhesives (ICA) are an alternative to solder reflow process, the ICA materials usually require up to $80 \mathrm{wt} \%$ of metal filler to achieve minimum electrical conductivity. Such a high concentration of filler not only deteriorates the mechanical properties of the polymer matrix but also increases greatly the weight of components. In aerospace, which requires high bonding strengths and durability of the adhesives, the polymer adhesives have been used for manufacturing of primary aircraft fuselage and wing structures. Comparing to the riveted joining, the use of polymer adhesives results in lighter weight, lower cost and more uniform distribution of stresses over the continuous bonded area. Nevertheless, the joint durability has been one of the major concerns as polymer adhesives usually suffer from poor mechanical strength and poor adhesion on metal substrates, especially under humid conditions $^{[3,4]}$. Therefore, it is necessary to develop polymer adhesives with high electrical conductivity and bonding strength at low conductive filler loading to meet the requirements of different industries.

\section{Experimental}

\section{Materials}

EPIKOTE 240 based on bisphenol-A resin and bisphenol-F resin was used as epoxy matrix. EPI-CURE 3274 based on aliphatic amine was used as hardener. Multiwall carbon nanotubes purchased from a Chinese company was used as filler. The CNTs were synthesized by chemical vapor deposition with purity of $92 \%$. They have an outer diameter about $20 \mathrm{~nm}$ and a length of a few microns.

Unclad 2024-T3 aluminum-copper alloy with aluminum fraction of $90.7-94.7 \%$ was used as metal plates to form joints with adhesives. This alloy has good mechanical 
properties with ultimate tensile strength of $448 \mathrm{MPa}$, tensile yield strength of $310 \mathrm{MPa}$ and elastic modulus of $73.1 \mathrm{GPa}^{[5]}$

\section{Pretreatment of the metal substrate}

In order to attain maximum joint performance, alternative current (AC) and direct current (DC) anodisation was used to pretreat the substrate surfaces.

Before anodisation, degreasing was conducted in acetone bath at ambient temperature under sonication for at least 5 minutes to remove oil content on the substrate surface. Then, ACDC anodising was carried out in a mixed acid of 5\% dilute solution containing $2.5 \%$ phosphoric and $2.5 \%$ sulphuric acid. AC anodising was carried out for 2 minutes at $15 \mathrm{~V} \mathrm{AC}, 35^{\circ} \mathrm{C}$ to produce a thin, electrochemically stable, hydration resistant, porous oxide layer. This was followed by 10 minutes $\mathrm{DC}$ anodising at $20 \mathrm{~V}, 35^{\circ} \mathrm{C}$ to produce a thick barrier oxide, giving good corrosion resistance to the substrate. The pretreatment then produced an oxide, grown outwards from the metal-oxide interface that was porous, yet electrochemically stable and consisted of sufficient thickness to act as a barrier against corrosion. ${ }^{[6]}$

\section{Preparation of carbon nanotube reinforced epoxy adhesive}

There are two steps to prepare CNTs filled epoxy adhesives. In the first step, CNTs were added into the hardener of EPI-CURE 3274 as the viscosity of it is much lower than the resin of EPIKOTE 240. The mixture was firstly mechanically stirred at $1500 \mathrm{rpm}$ for 1 hour at room temperature. It was then ultrasonicated for a further 30 minutes for better distribution of the CNTs. In the second step, the EPIKOTE 240 resin was added into the mixture obtained from the first step. The weight ratio of epoxy resin and hardener was 5:3. Again, the mixture was undergone mechanical mixing at $1500 \mathrm{rpm}$ for 30 minutes, followed by ultrasonication for another 30 minutes. Ice bath was used in this ultrasonication in order to reduce the temperature and prevent early curing of the mixture. After ultrosonication, the mixture was put into a vacuum chamber for about 30 minutes to remove bubbles trapped in the mixture while stirring. 
Preparation of aluminum joints with carbon nanotube reinforced epoxy adhesive

A drawdown block, designed in house to control the thickness of the adhesives, was used to apply the adhesives on the pretreated metal substrates. Firstly, the adhesive with thickness of $250 \mu \mathrm{m}$ was applied uniformly on one piece of the metal surface, it was then bonded carefully to another piece of uncoated substrate. The dimension of the metal plates were $150 \times 25 \times 3.2 \mathrm{~mm}$, which is accordance to the wedge test standard.

\section{Characterization}

The dispersion of the carbon nanotubes in epoxy matrix was observed with a field emission scanning electron microscope (FESEM, Jeol JSM 6340F).

The surface resistivity of the adhesives was determined by four-probe method (MCPT410, Mitsubishi Chemical Corporation).

Thermal stability of the adhesives was obtained by thermogravimetric analyzer (TGA Q500, TA Instruments) heating rate of $10^{\circ} \mathrm{C} / \mathrm{min}$.

Bonding strength and durability of aluminum joints was determined with Boeing wedge test in accordance with ASTM D-3762 ${ }^{[7]}$ and Boeing Spec BSS $7208 .^{[8]}$ The configuration of the specimen is shown in Figure 1. ${ }^{[7]}$

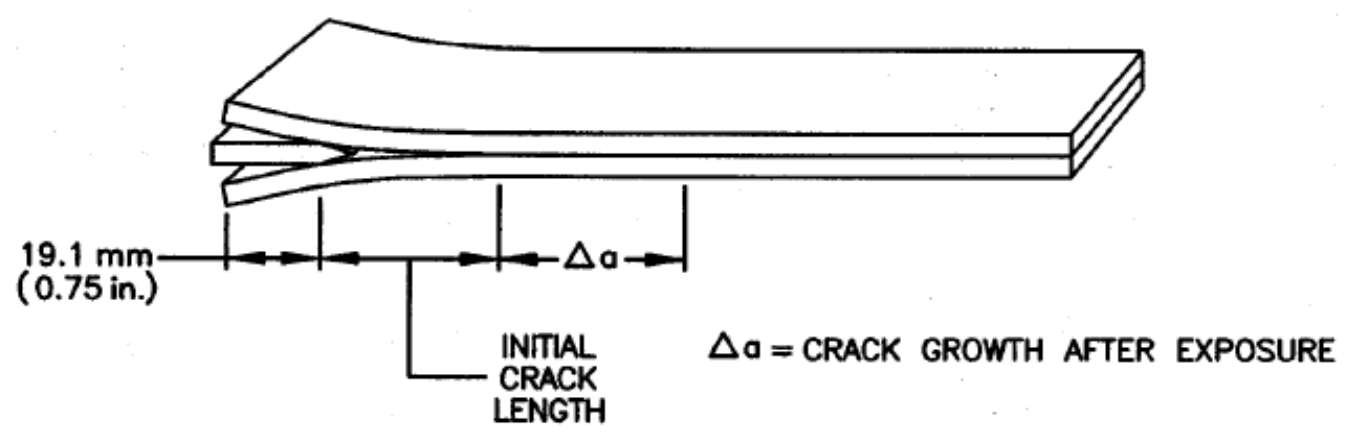

Figure 1. Configuration of wedge test specimen ${ }^{[7]}$

The Boeing wedge test consisted of two steps. Firstly, the wedge was inserted into the aluminum joints using a Hounsfiled tensometer under constant load and speed. The crack growth was allowed to equilibrate at ambient conditions over several hours. Secondly, the joints were immersed into water of $60^{\circ} \mathrm{C}$. They were removed from the water on 
periodical intervals and measurements were made on the crack propagation with the use of a profile projector as a function of immersion time for a period of up to $90 \mathrm{hrs}$ to establish the relative bond durability performance of the joints in the humid environment.

\section{Results and Discussion}

\subsection{Dispersion of CNTs into the epoxy matrix}

Two methods were used to fabricate CNT reinforced epoxy adhesive, one is mechanical stirring, another one is mechanical stirring with ultrasonication.

In the initial stage of the work, high speed shear mixer was used to disperse carbon nanotubes into the hardener of EPI-CURE 3274 and the resin of EPIKOTE 240. Poorly dispersion of CNTs in the epoxy matrix was found as the aggregates formed by the nanotubes could be seen clearly even under visual inspection. However, if the mixing speed increased, there was also increase in bubble generation, the mixture even turned foamy when the speed increased to $5000 \mathrm{rpm}$ and these bubbles were difficult to remove even under vacuum before curing.

In order to improve the distribution of CNTs in the polymer, mechanical stirring followed by ultrasonication was developed to prepare the adhesives, which was described in detail in Experimental section. With this approach, the small amount of bubble generated was easy to remove by vacuum. The morphology of CNT filled epoxy adhesive was observed by FESEM as shown in Figure 2.
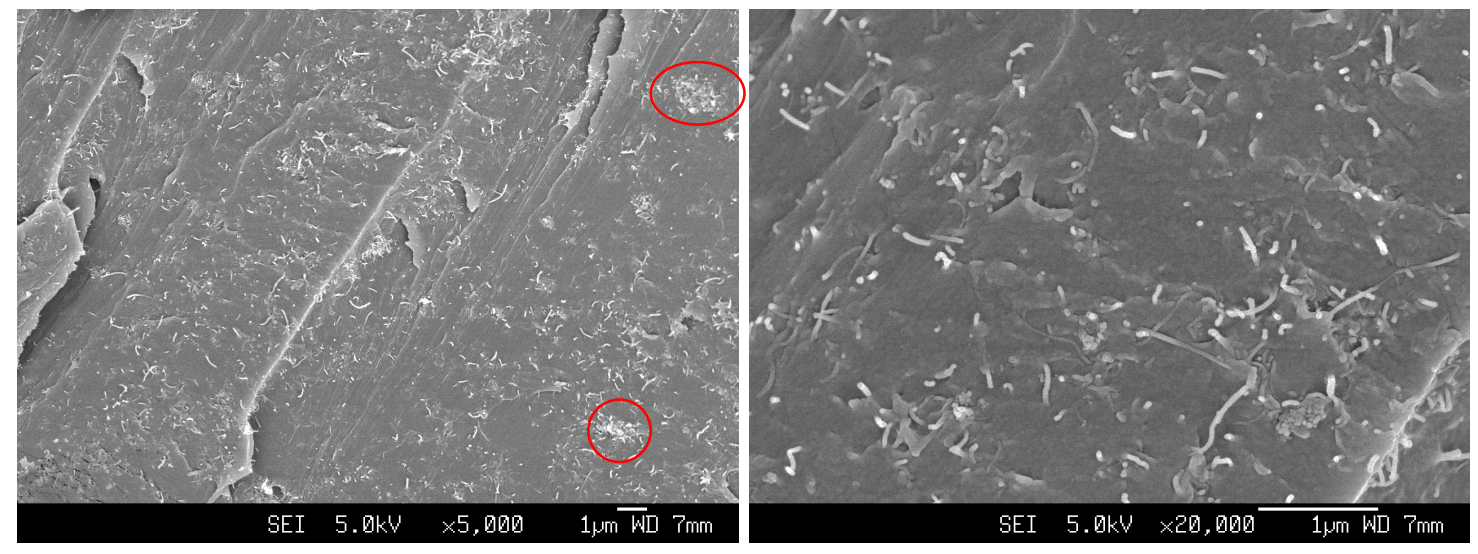

Figure 2. FESEM micrograph of 5 wt \% MWNTs/epoxide 
The uneven surface in Figure 2 was due to the slice mark caused during sample preparation. The CNTs dispersed quite homogenously in the epoxy, only a few small aggregated bundles could be observed as indicated in red circle in FESEM micrograph. Additionally, the nanofillers were scattered randomly in the epoxy matrix in all directions, providing the enhanced properties in all directions. There was no apparent aggregation and damage of the nanotubes in the epoxy, suggesting suitable processing procedures and parameters used to disperse the CNTs into the epoxy.

Mechanical stirring with ultrasonication has been proofed to be an effective way to uniformly distribute the nanotubes without the aid of any solvents. While solvents may be able to better facilitate the dispersal process, incomplete removal of the solvent, however, can result in defect formation as it evaporates during cure, or plasticisation of the cured polymer causing low mechanical and/or thermal properties.

\subsection{Electrical properties of the adhesives}

Epoxy is an excellent insulating material, while carbon nanotubes have electrical characteristics that are similar to metallic/semi-metallic materials, the addition of the CNTs into the polymer, therefore, will improve its electrical conductivity. Figure 3 shows the surface resistivity of the adhesives, measured at room temperature, as a function of CNT concentration.

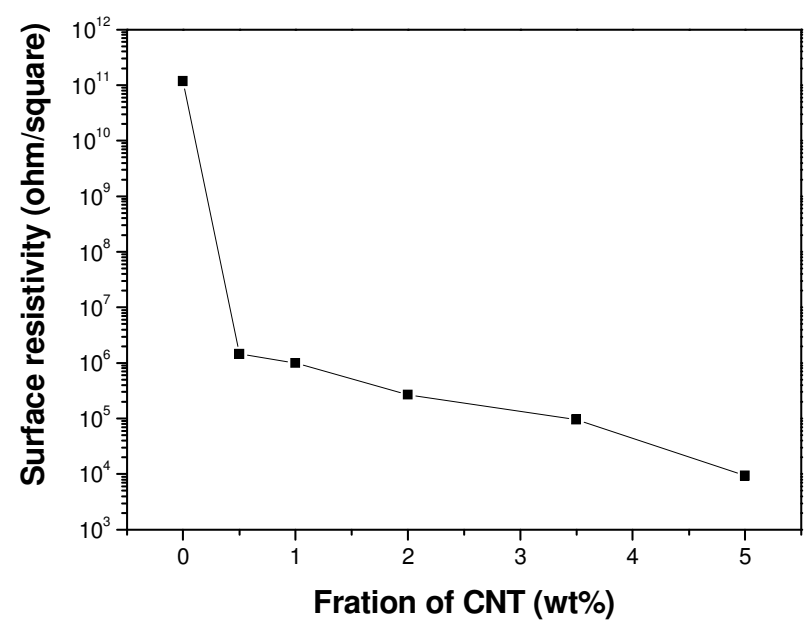

Figure 3. Electrical performance of the CNT filled epoxy adhesives 
The electrical resistivity decreased monotonously with CNT fraction and exhibited a percolation. The percolation threshold, a critical concentration of filler where the resistivity starts to reduce abruptly, was not more than $0.5 \mathrm{wt} \%$ of CNTs. The surface electrical resistivity of the samples changed over more than 5 orders of magnitude in this range. Further increasing the amount of CNTs beyond the percolation threshold, the surface electrical resistivity only decreased in lower pace. The percolation threshold of the CNT filled polymer is very low as compared to spherical carbon particle filled polymers which is at least $20 \mathrm{wt} \%$. This is resulted from the high aspect ratio of CNT filler and homogeneous dispersion of the CNTs in the polymer matrix.

\subsection{Thermal properties of the adhesives}

Figure 4 shows the TGA profiles as a function of CNT fraction.

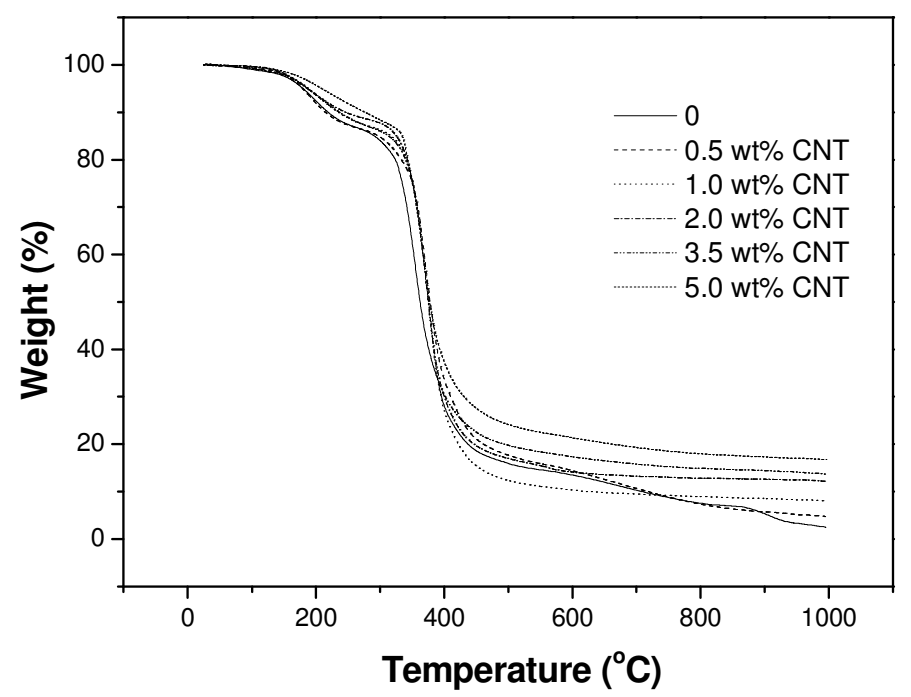

Figure 4. TGA profile of the fully cured adhesives with different amount of CNTs

It can be seen that all the adhesives with different amount of CNTs underwent two stages of weight loss from room temperature to about $1000^{\circ} \mathrm{C}$. The first stage weight loss happened below about $200^{\circ} \mathrm{C}$, possibly due to the decomposition of lower molecular weight materials. The second stage weight loss was between $320^{\circ} \mathrm{C}$ to $340^{\circ} \mathrm{C}$, related to the degradation of the 
epoxy of higher molecular weight formed during curing. Table I tabulates the onset decomposition temperature of the adhesives with different amount of CNTs.

Table I. Thermal properties of CNT filled epoxy adhesives

\begin{tabular}{|c|c|}
\hline $\begin{array}{c}\text { CNT fraction } \\
(\mathrm{wt} \%)\end{array}$ & $\begin{array}{c}\mathrm{T}_{\mathrm{c}} \\
\left({ }^{\circ} \mathrm{C}\right)\end{array}$ \\
\hline 0 & 325.64 \\
\hline 0.5 & 334.90 \\
\hline 1 & 339.76 \\
\hline 2 & 337.02 \\
\hline 3.5 & 332.30 \\
\hline 5 & 335.87 \\
\hline
\end{tabular}

The onset of decomposition of the nanocomposites occurred at higher temperatures than that of neat epoxy. The increment was about $14.1^{\circ} \mathrm{C}$ for $1 \mathrm{wt} \%$ of CNT filled epoxy adhesive as compared to the neat epoxy. The incorporation of CNTs into the epoxy offers a evident stabilizing effect. However, the amount of CNTs has no significant effect on the thermal stability of the adhesives.

\subsection{Wedge test of aluminum joints using CNT reinforced epoxy as adhesives}

Epoxy adhesives with different amount of CNTs were used to bond aluminum plates together, the bond strength and durability of the joints was investigated by Boeing wedge test. In the wedge test, firstly, the wedge was introduced at an imposed constant speed then the crack propagated at its own rate until it reached an equilibrium length. It is therefore, possible to directly investigate the consequences of varying CNT fraction on the adhesive strength. Figure 5 shows the crack propagation for unclad aluminum wedge samples up to 90 hours of immersion in water of $60^{\circ} \mathrm{C}$. 


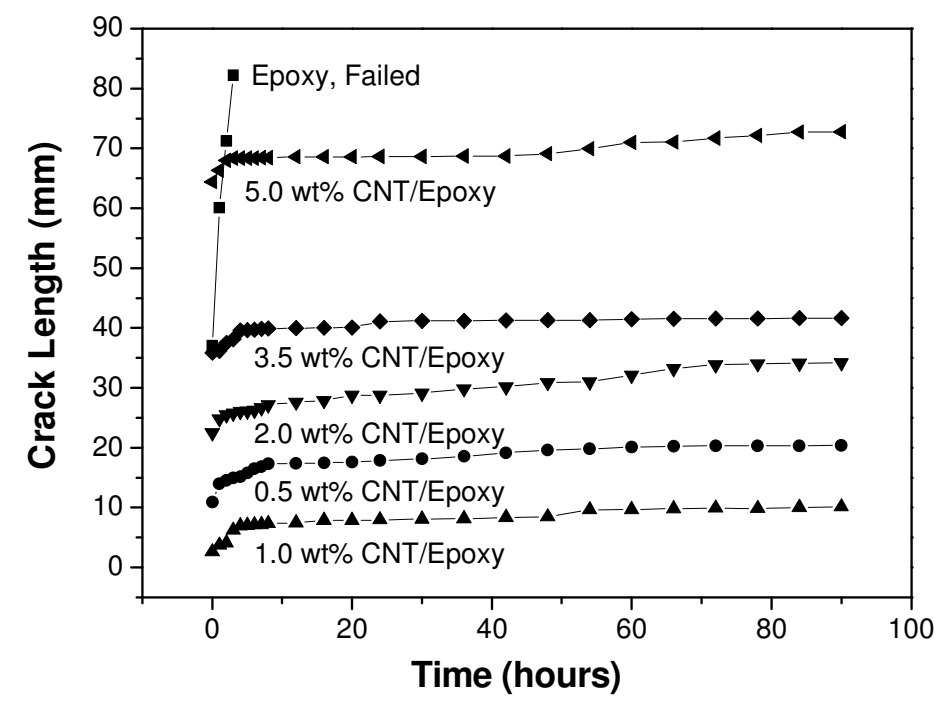

Figure 5. Crack propagation of aluminum joints for 90 hours under water of $60^{\circ} \mathrm{C}$

Among the six samples tested, the joint with neat epoxy failed after $3 \mathrm{hrs}$ of humidity test at $60^{\circ} \mathrm{C}$, while the rest of the joints with $0.5,1.0,2.0,3.5,5.0 \mathrm{wt} \%$ of CNTs remained bonded after 90 hours.

The initial crack length, measured after inserting the wedge at immersion time of 0 hour, was greatly affected by the addition of CNTs. The initial crack length was about 37 $\mathrm{mm}$ for the joint with neat epoxy. It decreased with the incorporation of CNTs, the initial crack length was about $10.9 \mathrm{~mm}$ and $2.65 \mathrm{~mm}$ for the joint with $0.5 \mathrm{wt} \%$ and $1.0 \mathrm{wt} \%$ of CNTs, respectively. However, further increase of CNTs from 2 to $5 \mathrm{wt} \%$ caused increase in the initial crack length up to $64.4 \mathrm{~mm}$ for the joint with $5.0 \mathrm{wt} \%$ of CNTs.

The crack developed with time after the joints were immersed into water of $60^{\circ} \mathrm{C}$. The development, however, was very different for the joints with and without CNTs. For the joint without CNTs, the crack developed very fast, the joint failed by becoming two pieces after 3 hours of the test. For the joints bonded with CNT filled adhesives, the propagation of cracks were only obvious in the first 3 to $8 \mathrm{hrs}$, after that the crack development slowed down. For the joint with $5 \mathrm{wt} \%$ of CNTs, although its initial crack length was greater than the joint with neat epoxy, it remained bonded after 90 hours of the test. The incorporation of CNTs does improve the bonding strength and durability of 
the joints. This may attribute to the excellent mechanical and hydrophobic properties of the carbon nanotubes. The multiwall carbon nanotubes themselves have very high mechanical properties with Young's modulus and yield strength of about $1 \mathrm{TPa}$ and 150 GPa, respectively, ${ }^{[9,10]}$ thus, even a small amount of CNTs incorporating into epoxy will greatly enhance its mechanical properties. ${ }^{[11,12,19]}$

The joint with $1 \mathrm{wt} \%$ of CNT reinforced adhesive has the lowest initial crack length and best durability under the experimental conditions here. Agglomerates of CNTs in the epoxy may exist at CNT concentration higher than $1 \mathrm{wt} \%$, which affect the durability performance of the adhesives.

\section{Conclusions}

Carbon nanotube reinforced epoxy adhesives were successfully developed by use of mechanical stirring followed by ultrasonication. The carbon nanotubes distributed uniformly in the epoxy matrix with no obvious agglomerations at $1 \mathrm{wt} \%$ of CNTs. The electrical and thermal properties of the adhesives were investigated. It was found that the percolation threshold for surface electrical conductivity was less than $0.5 \mathrm{wt} \%$ of CNTs. The degradation temperature was also shown to increase with the addition of CNTs.

The adhesives were also used to bond aluminum plates, the bonding strength and durability were studied in terms of Boeing Wedge test. Both of them increased greatly with the incorporation of CNTs. The joint with 1 wt\% of CNT, in particular, showed lowest initial and final crack length among all the samples tested. 


\section{References}

1. Kinloch, A. J. Adhesion and adhesives: science and technology, $1^{\text {st }}$ Edition, Chapman \& Hall, London, 1987.

2. Watson, C. Handbook of Adhesion - Industrial applications of adhesives:

scope of adhesives; bonding cylindrical components, $2^{\text {nd }}$ Edition, John Wiley \& Sons, Ltd, 2005.

3. Bonniau, P.; Bunsell, A. R. J, Compos. Mater. 1981, 15, 272.

4. Singh, D. B.; Kumar, A.; Tayal, V. P.; Sanyal, B. J. Mater. Sci. 1988, 23, 3015.

5. http://www.matweb.com/search/SpecificMaterial.asp?bassnum=MA2024AT3.

6. G.W. Critchlow, Private Communication, 2007.

7. ASTM, Annual Book of Standards, Philadelphia, D3762, 2003.

8. Boeing Aircraft Company, Specification for adhesive joint durability testing, BSS 7208.

9. Dujardin, E.; Ebbesen, T. W.; Krishnan, A.; Yianilos, P.N.; Treacy, M. M. J. Phys. Rev. B, 1998, 58, 14013.

10. Demczyk, B.G.; Yang, Y. M.; Cumings, J.; Hetman, M.; Han, W.; Zettl A.;

Ritchie, R. O. Mater. Sci. Eng. A, 2002, 334, 173. 